\title{
Sistem Pendukung Keputusan Pemilihan Suplier Hasil Tani Gabah Menggunakan Metode AHP
}

\section{Decision Support System Selection of Grain Farming Suppliers Using AHP Method}

\author{
Patmawati Hasan*1, Akrilvalerat Deainert Wierfi ${ }^{2}$, Friden Elefri Neno ${ }^{3}$, Kusrini ${ }^{4}$ \\ 1,2,3,4 Magister Informatika Universitas AMIKOM Yogyakarta \\ J1 Ring Road Utara, Condongcatur, Sleman, Yogyakarta 55281 \\ e-mail: : *11 patmawatihasan@gmail.com, ${ }^{2}$ akrilvha8@gmail.com, ${ }^{3}$ nenofriden.e@gmail.com , \\ ${ }^{4}$ kusrini@amikom.ac.id
}

\begin{abstract}
Abstrak
Gabah merupakan bahan pokok dalam produksi beras di PB Hikmat Tiga Berlian. Untuk menghasilkan beras dengan kualitas yang baik maka dibutuhkan pula supplier yang terbaik dan berkualitas. Salah satu upaya untuk mendapatkan supplier tersebut adalah dengan melakukan pemilihan supplier hasil tani. Namun kendala yang terjadi saat ini adalah pengambilan keputusan pada pemilihan Supplier hasil tani gabah pada saat musim panen dengan kelebihannya masing-masing. Hal ini dikarenakan petani yang membawa hasil tani hari ini dan esok hari adalah petani-petani yang berbeda. Penelitian ini bertujuan untuk merncang sistem pendukung keputusan pemilihan suplier hasil tani gabah menggunakan metode AHP. Prototype Sistem dibangun menggunkan Bahasa pemrograman PHP dan database MySQL. Sistem ini menghasilkan Supllier terpilih untuk menyuplai gabah di PB Hikmat Tiga Berlian. Kriteria yang digunakan adalah kadar air, kadar hampa, harga, jarak lahan ke pabrik, dan transportasi. Penelitian ini menyimpulkan bahwa perancangan prototype sistem pendukung keputusan berhasil dilakukan berdasarkan hasil pengujian User Acceptance Test dengan menggunakan 10 Responden dan 5 pertanyaan bahwa sistem dengan menggunakan metode AHP Dalam pemilihan Supplier dapat diterapkan. Hal ini didasarkan pada nilai rata-rata hasil $68 \%$ responden menjawab Sangat Setuju dan $26 \%$ responden menjawab Setuju. Pengujian terhadap hasil output sistem dan hasil perhitungan manual tidak ditemukan perbedaan hasil.
\end{abstract}

Kata kunci-Gabah, Supplier, SPK, AHP

\begin{abstract}
The grain is a staple in rice production in PB Hikmat Tiga Berlian. To produce good quality rice, the best and quality suppliers are needed. One effort to get these suppliers is by selecting a supplier of agricultural products. However, the obstacle that occurs at this time is the decision making on the selection of suppliers of grain crops during the harvest season with their respective advantages. This is because farmers who bring their crops today and tomorrow are different farmers. This study aims to develop a decision support system for the selection of suppliers of grain farming using the AHP method. This system will produce the names of suppliers chosen to supply grain in PB Hikmat Tiga Berlian. The criteria used are water content, vacuum content, price, distance to the factory, and transportation This study concludes that the DSS prototype design can be done based on the test results of the User Acceptance Test using 10 respondents and 5 questions that the system that uses the AHP method in supplier selection can be applied. This is based on the average value of the results. $68 \%$ of respondents answered
\end{abstract}


Strongly Agree and 26\% of respondents answered Agree. Testing the results of the system and the results of manual calculations found no difference in results.

Keywords-Grain, Suppliers, DSS, AHP

\section{PENDAHULUAN}

PB. Hikmat Tiga Berlian merupakan salah satu pabrik beras terbesar yang berada di Wilayah Sulawesi Selatan. Produksi dan hasil berasnya langsung dari Kabupatan SIDRAP yang biasanya disebut gudangnya beras di wilayah Sulawesi Selatan. PB. Hikmat Tiga Berlian melayani untuk Industri Skala Besar, Kecil, Juga Eceran Dengan Harga Kompetitif. Pada saat musim panen telah tiba banyak supplier petani yang menawarkan hasil tani gabah di PB. Hikmat Tiga Berlian. Namun yang membawa hasil tani hari ini dan esok hari adalah supplier - supplier yang berbeda. Maka pemilik membutuhkan sistem untuk dapat mengambil keputusan setiap hari atau sesuai dengan waktu yang ditentukan untuk memilih gabah yang berkualitas untuk diloah menjadi beras yang berkulitas baik untuk dipasarkan.

Dengan perkembangan ilmu pengetahuan dan teknologi sangat pesat didalam setiap aktifitas, penerapan TI untuk menunjang pekerjaan perusahaan, instansi pemerintahan dan perseorangan. Teknologi digunakan sebagai alat untuk dalam mempermudah pekerjaan manusia, setiap pekerjaan selalu dihadapkan dalam pengambilan keputusan dan masalah yang sukar untuk diselesaikan seperti dalam menentukan suatu pilihan oleh karena itu dalam perkembangan TI diterapkan sistem pendukung keputusan ( Decision support System) adalah bagian dari sistem informasi komputer yang berisi basis pengetahuan yang digunakan untuk mendukung dalam pengambilan keputusan yang mengolah data menjadi informasi untuk mengambil keputusan dari masalah semi terstruktur yang spesifik [1]. Salah satu upaya untuk mendapatkan supplier yang terbaik dan berkualitas tersebut adalah dengan melakukan pemilihan supplier [2]. Proses dalam penentuan supplier selama ini dilakukan secara manual dan kurang objektiv sehingga proses ini tentunya kurang efektif dan akurat karena akan merugikan PB. Hikmat Tiga Berlian. Oleh karena itu sistem pendukung keputusan pemilihan supplier yang terkomputerisasi sangat membantu PB. Hikmat Tiga Berlian yang kesulitan dalam memilih supplier dengan kelebihannya masingmasing. Pada penelitian ini menerapkan system pendukung keputusan menggunkan metode AHP (Analytic Hierarchy Process) adalah alat pengukuran kualitatif yang mengolah hal yang bersifat kuantitatif. Ada 3 keuntungan dalam penggunaan metode AHP yaitu penerapannya dalam masalah empiris mengarah ke solusi intuitif, hasilnya tidak mudah dimanipulasi dan dalam masalah keputusan memungkinkan membangun kepentingan relatif dari sejumlah kriteria [3]. Metode AHP memiliki struktur hirarkis dalam merepresentasikan tipe hubungan ketergantungan fungsional yang paling sederhana dan berurutan sehingga mempermudah mendekomposisikan persoalan multikriteria yang kompleks menjadi elemen-elemen keputusannya. Hirarki bersifat linear dan distrukturkan mulai dari elemen keputusan yang bersifat umum (misalnya tujuan, objektif, kriteria, dan subkriteria) sampai ke variabel atau faktor yang paling konkrit dan mudah terkontrol pada level hirarki terbawah yaitu alternatif keputusan [4].

Dari hasil penelitian yang dilakukan sebelumnya, implementasi metode AHP dalam sistem pendukung keputusan yang dilakukan oleh Anu John, dkk, dapat memberikan rekomendasi pemilihan vendor bahan baku kepada perusahaan FMCG untuk dapat mengurangi waktu dalam pemilihan vendor [5]. Selanjutnya dengan menggunakan metode AHP yang bertujuan menggunakan alat objektif untuk membangun model seleksi pemasok dengan mempertimbangkan beberapa kriteria prioritas kompetitif seperti kualitas, biaya, pengiriman, dan fleksibilitas sebagai kriteria evaluasi dan seleksi [6].

Penelitian yang menyajikan aplikasi menggunakan metode Analytic Hierarchy Process (AHP) bertujuan dalam mengevaluasi dan pemilihan supplier untuk perusahaan Big C di Vietnam [7]. Penelitian dengan fitur sistem pendukung keputusan memungkinkan distributor yang paling 
cocok, serta moda transportasinya, dipilih oleh pengguna berdasarkan evaluasi umum moda transportasi menggunakan metode Analytic Hierarchy Process (AHP) yang bertujuan untuk mengakomodasi distributor dan moda transportasi yang sesuai berdasarkan karakteristik produk yang diperdagangkan dengan hasil peneilitian ini menghitung kapasitas angkutan menjadi kriteria dalam waktu pengiriman [8]. Pemilihan traktor terbaik di kota-kota Ghaenshahr dan Ahvaz Iran. Populasi statistik penelitian ini adalah 25 traktor di Ghaemshahr dan Ahvaz, di Pakistan 15 traktor dipilih secara acak, dan data dianalisis menggunakan AHP [9]. Keunggulan dari metode AHP ini adalah sebuah hirarki fungsional dimana input utamanya adalah persepsi manusia. Dengan hirarki, suatu masalah yang kompleks dan tidak terstruktur dipecahkan ke dalam kelompokkelompoknya. Kemudian kelompok-kelompok tersebut diatur menjadi suatu bagian hirarki [10].

Pada penelitian ini penggunan metode AHP dalam sistem pendukung keputusan pemilihan Supplier hasil tani gabah di PB. Hikmat Tiga Berlian agar membantu pemilik (pengguna sistem) akan hasil perangkingan supplier yang dihasilkan akurat dan terkomputerisasi dalam pengambilan keputusan. Alasan penggunaan metode AHP karena dapat memberikan hasil akurat yang didapatkan dari perbandingan kriteria dan subkriteria serta data-data dari supplier, serta mampu memberikan keputusan berupa supplier yang terpilih untuk memasukkan gabah di PB. Hikmat Tiga Berlian.

\section{METODE PENELITIAN}

Metode yang digunakan dalam penelitian ini menggunakan metode AHP dalam sistem pendukung keputusan pemilihan Supplier hasil tani gabah di PB. Hikmat Tiga Berlian. Dengan teknik pengumpulan data yaitu wawancara, observasi, studi dokumentasi dan pembagian kuesioner dengan tujuan informasi yang diterima berkaitan langsung dengan kegiatan-kegiatan yang dilakukan.Tahap-tahap pada penelitian ini yaitu analisis, desain, pengkodean, dan pengujian. Seperti pada gambar 1 berikut ini [11]:

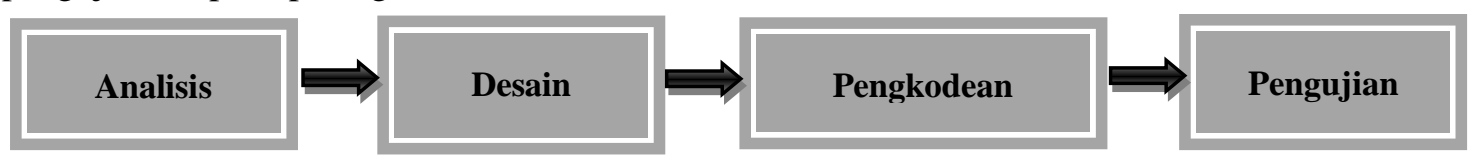

Gambar 1 Metode Penelitian

Keterangan:

a. Analisis

Pada tahap analisis kebutuhan-kebutuhan yang dikumpul secara detil untuk menspesifikasikan kebutuhan user agar mudah di gunakan sistem pendukung keputusan yang memenuhi kebutuhan user. Seperti melakukan pengumpulan data dan analisis data yang dibutuhkan dalam perancangan sistem.

b. Desain

Desain sistem adalah proses yang merancamg permodelan sistem menggunakan metode AHP termasuk juga desain sistem yang diantaranya desain proses dengan menggunakan Diagram Konteks, desain Database, dan desain User Interface. Tahap-tahap ini menjelaskan kebutuhan sistem dari tahap analisis kebutuhan ke representasi desain agar dapat diimplementasikan menjadi program ke tahap selanjutnya.

c. Pengkodean

Dari tahap desain yang sudah dibuat harus di iplementasikan kedalam perangkat lunak yang akan menjadi sebuah sistem. Hasil dari tahap pengkodean berupa sistem pendukung keputusan atau program komputer yang sesuai dengan tahap desain yang dibuat sebelumnya.

d. Pengujian

Pengujian fokus pada perangkat lunak dari segi lojik dan fungsional dan memastikan bahwa semua bagian dari segi lojik dan fungsional sudah diuji. Hal ini dilakukan untuk meminimalisir 
kesalahan (error) dan untuk mengetahui tingkat keakurasian dari sistem dan tingkat penerimaan terhadap sistem dari calon pengguna.

\subsection{Analytic Hierarchy Process (AHP)}

Pada dasarnya metode AHP merupakan suatu teori umum tentang suatu konsep pengukuran. Metode ini digunakan untuk menemukan suatu skala rasio baik dari perbandingan pasangan yang bersifat diskrit maupun kontinu. Perbandingan-perbandingan ini dapat diambil dari ukuran aktual atau dari suatu skala dasar yang mencerminkan kekuatan perasaan dan prefensi relatif [12]. Hasil akhir dari proses AHP adalah prioritas - prioritas dari alternatif - alternatif yang menjadi pilihan. Prioritas tersebut dapat digunakan untuk menentukan alternatif terbaik. Dengan AHP, proses keputusan kompleks dapat diuraikan menjadi keputusan-keputusan lebih kecil yang dapat ditangani dengan mudah. Cara kerja AHP adalah dengan menyederhanakan suatu permasalahan kompleks yang tidak terstruktur, strategik dan dinamik menjadi bagian-bagian yang lebih sistematis. Berikut ini merupakan langkah-langkah perhitngan AHP [13] :

a. Membuat struktur hirarki yang diawali dengan tujuan umum, dilanjutkan dengan subtujuansubtujuan, kriteria dan kemungkinan alternatif-alternatif pada tingkatan kriteria yang paling bawah.

b. Membuat matriks perbandingan berpasangan pada intensitas. Perbandingan dilakukan berdasarkan "judgment" dari pengambil keputusan dengan menilai tingkat kepentingan suatu elemen dibandingkan elemen lainnya. Sehingga diperoleh judgment seluruhnya sebanyak $\mathrm{n}$ * [(n-1)/2] buah, dengan $\mathrm{n}$ adalah banyaknya elemen yang dibandingkan. Kemudian menentukan prioritas lokalnya dan menghitung konsistensinya.

c. Melakukan operasi perkalian antara matriks yang memuat prioritas lokal kriteria dengan matriks yang memuat prioritas lokal intensitas / alternatif sehingga akhirnya akan menghasilkan suatu prioritas global.

d. Memeriksa elemen matriks jika aij * ajk = aik maka penilaian pada matriks tersebut sudah konsisten jika tidak maka lakukan perhitungan dengan rumus untuk menghitung konsistensi rasionya. Jika nilainya lebih dari 10 persen maka penilaian data judgment harus diperbaiki.

Untuk menghitung konsistensi dari matriks perbandingan berpasangan dibutuhkan consistency random (CR). Berdasarkan perhitungan Saaty dengan menggunakan 5 sampel, jika "judgment" numerik diambil secara acak dari skala 1/9, 1/8, .., 1, 2, ., 9 akan diperoleh ratarata konsistensi untuk matriks dengan ukuran yang berbeda.

\section{HASIL DAN PEMBAHASAN}

\subsection{Struktur Hirarki Metode AHP}

Struktur hirarki dengan menggunakan metode Analytic Hierarchy Process (AHP) digunakan untuk pemilihan Supplier hasil tani gabah di PB. Hikmat Tiga Berlian agar membantu pemilik (pengguna sistem) akan hasil perangkingan supplier. Struktur hirarki ditunjukkan pada Gambar 2. 


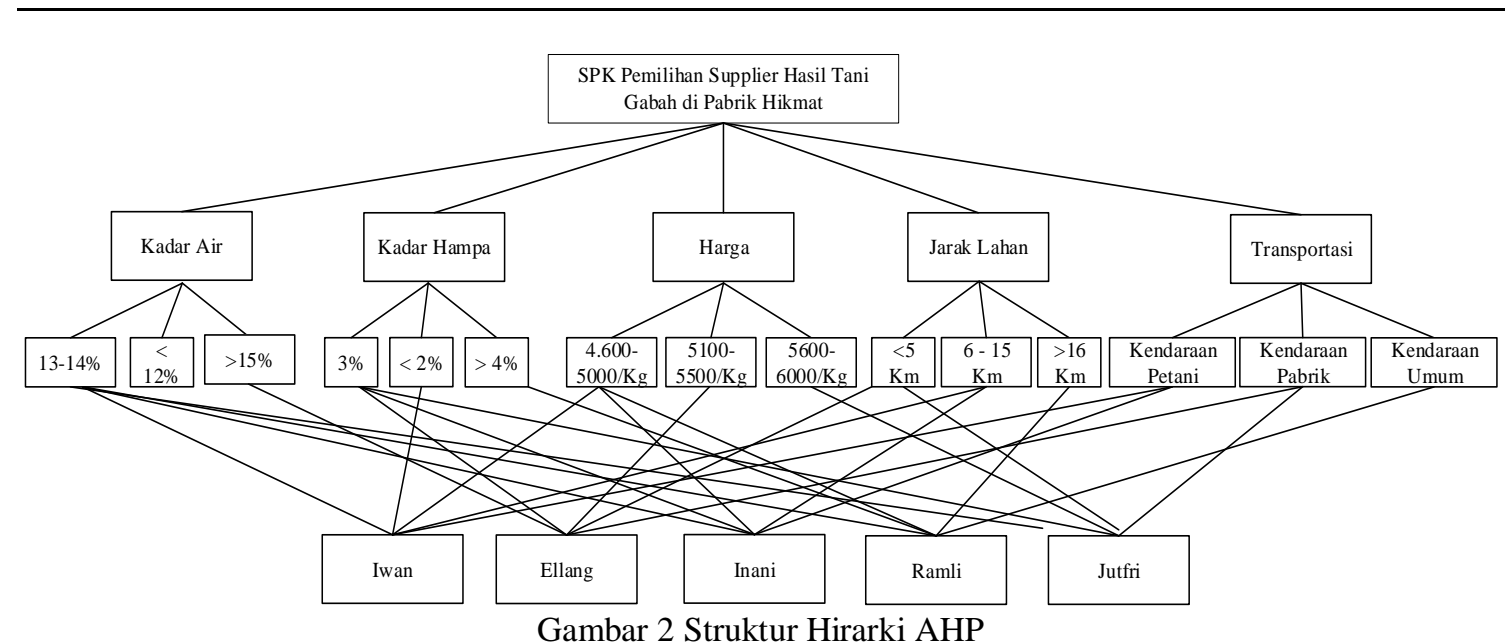

\subsection{Analisis}

PB. Hikmat Tiga Berlian merupakan salah satu pabrik beras yang bergerak di bidang pengolahan gabah dan beras serta distribusi beras. Untuk menghasilkan beras dengan kualitas yang baik maka dibutuhkan pula supplier yang terbaik dan berkualitas. Proses dalam penentuan supplier selama ini dilakukan secara manual dan kurang objektif sehingga proses ini tentunya kurang efektif dan akurat karena akan merugikan PB. Hikmat Tiga Berlian. Untuk informasi yang menjadi kebutuhan dalam proses pembuatan sistem dengan melakukan wawancara, observasi, studi dokumentasi dan pembagian kuesioner. Data supplier dilihat pada pada tabel 1.

Tabel 1 Data Supllier

\begin{tabular}{ccc}
\hline No & Kode & Nama Supplier \\
\hline 1 & A01 & Iwan \\
\hline 2 & A02 & Ellang \\
\hline 3 & A03 & Inani \\
\hline 4 & A04 & Ramli \\
\hline 5 & A05 & Jutfri \\
\hline
\end{tabular}

Kriteria yang digunakan dalam proses pemilihan supplier dilihat pada tabel 2.

Tabel 2 Data Kriteria

\begin{tabular}{ccc}
\hline No & Kode & Kriteria \\
\hline 1 & F01 & Kadar Air \\
\hline 2 & F02 & Kadar Hampa \\
\hline 3 & F03 & Harga \\
\hline 4 & F04 & Jarak Lahan \\
\hline 5 & F05 & Transportasi \\
\hline
\end{tabular}

Subkriteria pada masing-masing kriterai dilihat pada tabel 3.

Tabel 3 Data Subkriteria

\begin{tabular}{cccccc}
\hline NO & F01 & F02 & F03 & F04 & F05 \\
\hline 1 & $13-14 \%$ & $3 \%$ & $4.600-5000 / \mathrm{Kg}$ & $<5 \mathrm{Km}$ & Kendaraan Petani \\
\hline 2 & $<12 \%$ & $<2 \%$ & $5100-5500 / \mathrm{Kg}$ & $6-15 \mathrm{Km}$ & Kendaraan Pabrik \\
\hline 3 & $>15 \%$ & $>4 \%$ & $5600-6000 / \mathrm{Kg}$ & $>16 \mathrm{Km}$ & Kendaraan Umum \\
\hline
\end{tabular}

\subsection{Desain}

Penelitian ini menggunakan metode AHP sebagai permodelan dalam sistem ini. AHP digunakan dalam memilih supplier terbaik yang menjadi keputusan dalam pemilihan supplier hasil tani gabah. Berikut prosedur dalam metode AHP [1]:

a. Menentukan prioritas Kriteria

Langkah yang perlu dilakukan untuk menentukan prioritas kriteria sebagai berikut:

1. Membuat matriks perbandingan berpasangan

Dalam membuat matriks perbandingan berpasangan antara satu kriteria dengan kriteria yang lain menggunakan skala penilaian perbandingan berpasangan, seperti pada tabel 4 baris 
kriteria F01 (Kadar Air) memiliki nilai 2 kali mendekati penting terhadap baris kriteria F02 (Kadar Hampa) dan sebaliknya. Nilai perbandingan dari setiap kriteria diperoleh dari hasil pembagian kuesioner. Dan untuk menampilka nilai kriteria secara menyeluruh dari matriks perbandingan berpasangan seperti pada tabel 4 .

Tabel 4 Matriks Perbandingan Berpasangan

\begin{tabular}{|c|c|c|c|c|c|}
\hline Kode & F01 & F02 & F03 & F04 & F05 \\
\hline F01 & 1 & 2 & 2 & 4 & 5 \\
\hline F02 & 0,5 & 1 & 2 & 4 & 5 \\
\hline Kode & F01 & F02 & F03 & F04 & F05 \\
\hline F03 & 0,5 & 0,5 & 1 & 3 & 4 \\
\hline F04 & 0,25 & 0,25 & 0,3333 & 1 & 2 \\
\hline F05 & 0,2 & 0,2 & 0,25 & 0,5 & 1 \\
\hline Jumlah & 2,45 & 3,95 & 5,5833 & 12,5 & 17 \\
\hline
\end{tabular}

2. Membuat matriks nilai kriteria

Tahap selanjutnya membuat matriks nilai kriteria dengan persamaan 1 berikut [1]:

Nilai baris kolom baru $=\frac{\text { nilai baris-kolom lama }}{\text { jumlah masing kolom lama }}$

Nilai baris F01

$$
=\frac{1}{2,45}=0,4082
$$

Perhitungan diterapkan untuk semua baris kolom baru menggunakan persamaan 1 sehingga mendapatkan matriks ternormalisasi pada tabel 5.

Tabel 5. Matriks Nilai Kriteria

\begin{tabular}{cccccccc}
\hline Kode & F01 & F02 & F03 & F04 & F05 & $\begin{array}{c}\text { Jumlah } \\
\text { Baris }\end{array}$ & Prioritas \\
\hline F01 & 0,4082 & 0,5063 & 0,3582 & 0,32 & 0,2941 & 1,8868 & 0,3774 \\
\hline F02 & 0,2041 & 0,2532 & 0,3582 & 0,32 & 0,2941 & 1,4296 & 0,2859 \\
\hline F03 & 0,2041 & 0,1266 & 0,1791 & 0,24 & 0,2353 & 0,9851 & 0,197 \\
\hline F04 & 0,102 & 0,0633 & 0,0597 & 0,08 & 0,1176 & 0,4227 & 0,0845 \\
\hline F05 & 0,0816 & 0,0506 & 0,0448 & 0,04 & 0,0588 & 0,2759 & 0,0552 \\
\hline Jumlah & 1 & 1 & 1 & 1 & 1 & 5 & 1 \\
\hline
\end{tabular}

Nilai pada kolom prioritas merupakan hasil penjumlahan masing-masing baris dibagi dengan jumlah kriteria yang digunakan dengan menggunakan persamaan 2

$$
\begin{aligned}
& w i=\frac{a i}{n} \\
& \mathrm{w} 1=\frac{1,8868}{5}=0,3774
\end{aligned}
$$

Secara detil matriks prioritas kriteria menggunakan persamaan 2 dapat dilihat pada tabel 6

Tabel 6 Prioritas Kriteria

\begin{tabular}{cccccc}
\hline Kode & F01 & F02 & F03 & F04 & F05 \\
\hline Prioritas & 0,3774 & 0,2859 & 0,197 & 0,0845 & 0,0552 \\
\hline
\end{tabular}

3. Membuat matriks penjumlahan setiap baris

Langkah selanjutnya membuat matriks penjumlahan dengan mengalikan nilai prioritas pada tabel 6 dengan matriks perbandingan berpasangan pada tabel 4. Seperti nilai 0,3774 pada baris F01 tabel 7 diperoleh dari nilai prioritas F01 $(0,3774)$ dikalikan dengan nilai baris F01 dan kolom F01. Maka hasil perhitungan matriks penjumlahan setiap baris secara keseluruhan dapat dilihat pada tabel 7 .

Tabel 7 Matriks Penjumlahan Setiap Baris

\begin{tabular}{ccccccc}
\hline Kode & F01 & F02 & F03 & F04 & F05 & Jumlah Baris \\
\hline F01 & 0,3774 & 0,5718 & 0,3940 & 0,3381 & 0,2759 & 1,9572 \\
\hline F02 & 0,1887 & 0,2859 & 0,3940 & 0,3381 & 0,2759 & 1,4826 \\
\hline F03 & 0,1887 & 0,1430 & 0,1970 & 0,2536 & 0,2207 & 0,0030 \\
\hline F04 & 0,0943 & 0,0715 & 0,0657 & 0,0845 & 0,1103 & 0,4264 \\
\hline F05 & 0,0755 & 0,0572 & 0,0493 & 0,0423 & 0,0552 & 5,0000 \\
\hline Jumlah & 0,9245 & 1,1294 & 1,1000 & 1,0567 & 0,9379 & \\
\hline
\end{tabular}


4. Perhitungan rasio konsistensi

Selanjutnya melakukan perhitungan rasio konsistensi dengan cara membagi jumlah matriks setiap baris pada tabel 7 dengan nilai prioritas kriteria pada tabel 6. Sehingga di dapatkan perhitungan sebagai berikut:

$\begin{array}{lll}\text { F01 }=1,9572 / 0,3774 & =5,1866 \\ \text { F02 }=1,4826 / 0,2859 & =5,1856 \\ \text { F03 }=1,0030 / 0,1970 & =5,0908 \\ \text { F04 = } 0,4264 / 0,0845 & =5,0437 \\ \text { F05 = } 0,2793 / 0,0552 & =5,0632 \\ \text { Jumlah } & =\mathbf{2 5 , 5 6 9 8}\end{array}$

Selanjutnya mencari nilai $\lambda$ maks, CI dan CR dimana banyaknya kriteria (n) adalah 5 (lima):
$\lambda$ maks $=\frac{\text { Jumlah }}{n}=\frac{25,5698}{5}=5,1140$
$C I$
$=\frac{(\lambda \text { maks }-\mathrm{n})}{n-1}=\frac{5,1140-5}{5-1}=0,0285$
$C R=\frac{C I}{I R}=\frac{0,0285}{1,12}=0,0254$

Oleh karena hasil $\mathrm{CR}<0,1$ maka rasio konsistensi dari perhitungan tersebut dapat diterima.

b. Menentukan prioritas subkriteria

Selanjutnya perhitungan subkriteria yang dilakukan terhadap sub-sub dari lima kriteria sebelumnya. Terdapat 5 kriteria yang berarti akan ada 5 perhitungan prioritas subkriteria.

1. Menghitung prioritas subkriteria kadar air

Membuat matriks perbandingan subkriteria seperti matriks perbandingan kriteria, hasil perbandingan subkriteria kadar air pada tabel 8 .

Tabel 8 Matriks Perbandingan Subkriteria Kadar Air

\begin{tabular}{c|ccc}
\hline Kadar Air & $\mathbf{1 3 - 1 4 \%}$ & $<\mathbf{1 2 \%}$ & $\mathbf{1 5 \%}$ \\
\hline $\mathbf{1 3 - 1 4 \%}$ & 1 & 5 & 6 \\
\hline $\mathbf{1 2 \%}$ & 0,2 & 1 & 2 \\
\hline$>\mathbf{1 5 \%}$ & 0,1667 & 0,5 & 1 \\
\hline Jumlah & 1,3667 & 6,5 & 9 \\
\hline
\end{tabular}

Tahap selanjutnya membuat matriks nilai subkriteria kadar air pada tabel 9

Tabel 9 Matriks Nilai Subkriteria Kadar Air

\begin{tabular}{cccccc}
\hline Kadar Air & $\mathbf{1 3 - 1 4 \%}$ & $\mathbf{< 1 2 \%}$ & $\mathbf{> 1 5 \%}$ & Jumlah Baris & Prioritas \\
\hline $\mathbf{1 3 - 1 4 \%}$ & 0,7317 & 0,7692 & 0,6667 & 2,1676 & 0,7225 \\
\hline$<\mathbf{1 2 \%}$ & 0,1463 & 0,1538 & 0,2222 & 0,5224 & 0,1741 \\
\hline$>\mathbf{1 5 \%}$ & 0,1220 & 0,0769 & 0,1111 & 0,3100 & 0,1033 \\
\hline
\end{tabular}

Nilai pada kolom prioritas subkriteria merupakan hasil penjumlahan masing-masing baris dibagi dengan jumlah kriteria yang digunakan dengan menggunakan persamaan 2

$\mathrm{w} 1=\frac{2,1676}{3}=0,7225$

$\mathrm{w} 2=\frac{0,5224}{3}=0,1741$

w3 $=\frac{0,31}{3}=0,1033$

Dengan proses yang sama untuk perhitungan subkriteria kadar hampa, harga, jarak lahan dan transportasi sama dengan cara perhitungan yang dilakukan subkriteria kadar air.

c. Menghitung Hasil Perangkingan

Pada langkah-langkah yang telah dibuat sebelumnya dalam menentukan prioritas kriteria dan subkriteria yang akan digunakan dalam perhitungan pemilihan supplier. Dari hasil prioritas kriteria dan subkriteria dibuat matrik hasil pada tabel 10.

\section{Tabel 10 Matrik Hasil}

\begin{tabular}{ccccc}
\hline Kadar air & Kadar Hampa & Harga & Jarak Lahan & Transportasi \\
\hline 0,3774 & 0,2859 & 0,1970 & 0,0845 & 0,0552 \\
\hline
\end{tabular}


Patmawati Hasan, Akrilvalerat Deainert Wierfi, Friden Elefri Neno, Kusrini

\begin{tabular}{ccccc}
\hline & & & & \\
\hline $\mathbf{1 3 - 1 4 \%}$ & $\mathbf{3 \%}$ & $\mathbf{4 . 6 0 0 - 5 0 0 0 / K g}$ & $<\mathbf{5 m}$ & Kendaraan Petani \\
\hline 0,7225 & 0,5813 & 0,6924 & 0,6333 & 0,5390 \\
\hline$<\mathbf{1 2 \%}$ & $<\mathbf{2 \%}$ & $\mathbf{5 1 0 0 - 5 5 0 0 / K g}$ & $\mathbf{6 - 1 5} \mathbf{~ K m}$ & Kendaraan Pabrik \\
\hline 0,1741 & 0,3092 & 0,2233 & 0,2605 & 0,2973 \\
\hline$>\mathbf{1 5 \%}$ & $>\mathbf{4 \%}$ & $\mathbf{5 6 0 0 - 6 0 0 0 / K g}$ & $>\mathbf{1 6} \mathbf{~ K m}$ & Kendaraan Umum \\
\hline 0,1033 & 0,1096 & 0,0843 & 0,1062 & 0,1638 \\
\hline
\end{tabular}

Diketahui data nilai supplier yang ada di PB. Tiga Hikmat Berlian pada Tabel 11

Tabel 11 Data Nilai Supplier

\begin{tabular}{cccccc}
\hline ALT & Kadar air & Kadar Hampa & Harga & Jarak Lahan & Transportasi \\
\hline Iwan & $14 \%$ & $3 \%$ & 5700 & $4 \mathrm{Km}$ & Kendaraan Pabrik \\
\hline Ellang & $13 \%$ & $2 \%$ & 4600 & $14 \mathrm{Km}$ & Kendaraan Petani \\
\hline Inani & $16 \%$ & $3 \%$ & 5200 & $3 \mathrm{Km}$ & Kendaraan Pabrik \\
\hline Ramli & $14 \%$ & $3 \%$ & 4900 & $15 \mathrm{Km}$ & Kendaraan Petani \\
\hline Jutfri & $7 \%$ & $5 \%$ & 4600 & $18 \mathrm{Km}$ & Kendaraan Umum
\end{tabular}

Data nilai supplier akan dikonversi kedalam nilai prioritas subkriteria yang akan di hitung hasil akhir atau hasil perangkingan supplier pada Tabel 12

Tabel 12 Hasil Perangkingan Supplier

\begin{tabular}{cccccccc}
\hline \multirow{2}{*}{ ALT } & $\begin{array}{c}\text { Kadar } \\
\text { air }\end{array}$ & $\begin{array}{c}\text { Kadar } \\
\text { Hampa }\end{array}$ & Harga & Jarak Lahan & Transportasi & \multirow{2}{*}{ Total } & \multirow{2}{*}{ RANK } \\
\cline { 2 - 5 } & 0,3774 & 0,2859 & 0,1970 & 0,0845 & 0,0552 & & 3 \\
\hline Iwan & 0,7225 & 0,5813 & 0,0843 & 0,6333 & 0,2973 & 0,5254 & 3 \\
\hline Ellang & 0,7225 & 0,3092 & 0,6924 & 0,2605 & 0,5390 & 0,5492 & 2 \\
\hline Inani & 0,1033 & 0,5813 & 0,2233 & 0,6333 & 0,2973 & 0,3191 & 4 \\
\hline Ramli & 0,7225 & 0,5813 & 0,6924 & 0,2605 & 0,5390 & 0,6270 & 1 \\
\hline Jutfri & 0,1741 & 0,1096 & 0,6924 & 0,1062 & 0,1638 & 0,2515 & 5 \\
\hline
\end{tabular}

Nilai 0,7225 pada kolom Kadar Air baris Iwan didapatkan dari nilai Supplier Iwan untuk

Kadar air yaitu $14 \%$ dengan prioritas dari subkriteria $13-14 \%$ yang bernilai 0,7225 . Untuk kolom total menggunakan persaman 3

$$
\begin{aligned}
& S j=\Sigma i(S i j)(W i) \\
& \text { Iwan }=(0,3774 * 0,7225)+(0,2859 * 0,5813)+(0,1970 * 0,0843)+(0,0845 * 0,6333)+ \\
&(0,0552 * 0,2973)=\mathbf{0 , 5 2 5 4} \\
& \text { Ellang }=(0,3774 * 0,7225)+(0,2859 * 0,3092)+(0,1970 * 0,6333)+(0,0845 * 0,2605)+ \\
&(0,0552 * 0,5390)=\mathbf{0 , 5 4 9 2} \\
& \text { Inani }=(0,3774 * 0,1033)+(0,2859 * 0,5813)+(0,1970 * 0,2233)+(0,0845 * 0,6333)+ \\
&(0,0552 * 0,2973)=\mathbf{0 , 3 1 9 1} \\
& \text { Ramli }=(0,3774 * 0,7225)+(0,2859 * 0,5813)+(0,1970 * 0,6924)+(0,0845 * 0,2605)+ \\
&(0,0552 * 0,5390)=\mathbf{0 , 6 2 7 0} \\
& \text { Ramli }=(0,3774 * 0,1741)+(0,2859 * 0,1096)+(0,1970 * 0,6924)+(0,0845 * 0,1062)+ \\
&(0,0552 * 0,1638)=\mathbf{0 , 2 5 1 5}
\end{aligned}
$$

Pada tabel 12 didapatkan 3 supplier yang memiliki nilai total yang tinggi sehingga menjadi dasar pemilihan supplier yaitu Ramli, Ellang, dan Iwan.

d. Desain Proses

Penelitian ini merepresentasikan pemodelan proses menggunakan diagram konteks untuk menggambarkan aliran data yang mencakup masukan-masukan dasar, sistem umum dan keluaran serta menunjukkan sistem secara menyeluruh pada gambar 3 .

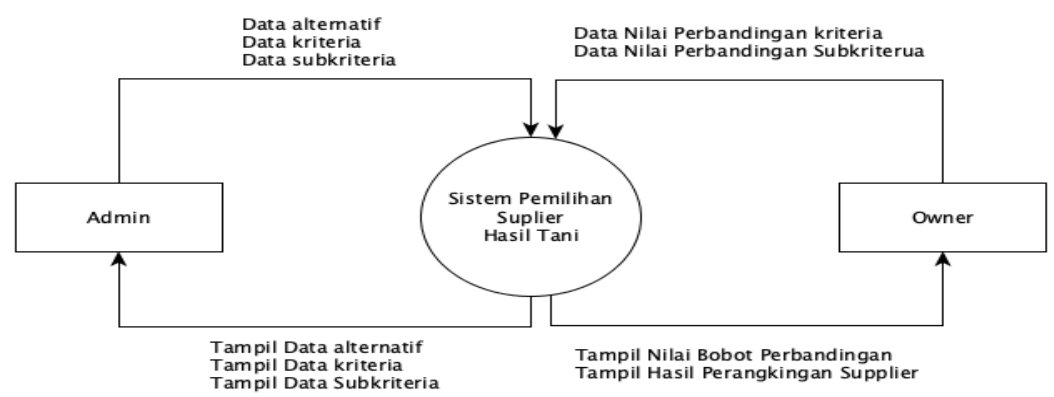

Gambar 3 Diagram Konteks Pemilihan Supplier 
Sistem Pendukung Keputusan Pemilihan Suplier Hasil Tani Gabah ...

e. Desain Basis Data

Rancangan relasi antar tabel yang akan dibuat pada sistem pendukung keputusan pemilihan supplier hasil tani gabah dapat dilihat pada gambar 4.

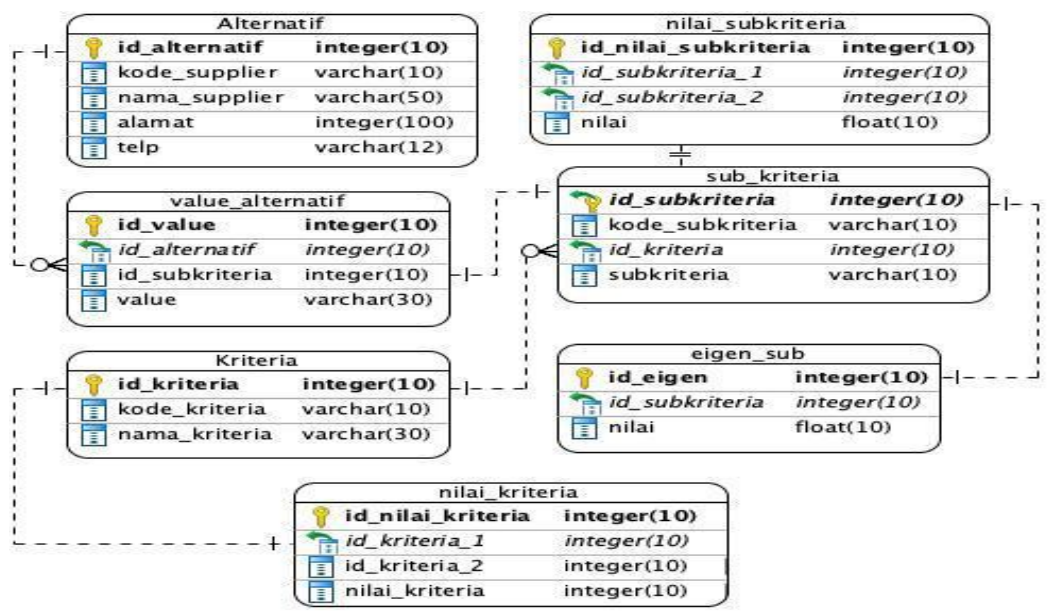

Gambar 4 Relasi Antar Tabel

\subsection{Implementasi}

Dalam penelititian ini ada lima fungsi utama yaitu input data alternatif, input detil alternatif, input kriteria dan subkriteria, input matriks berpasangan kriteria, input matriks berpasangan subkritertia dan perhitungan hasil analisa. Berikut ini implementasi user interface sistem pendukung keputusan pemilihan suplier hasil tani gabah menggunakan metode AHP:

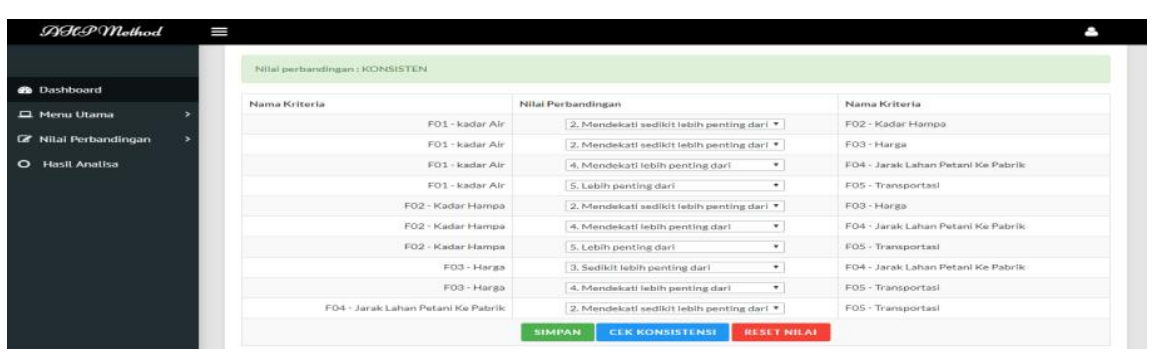

Gambar 5 Menu Perbandingan Kriteria

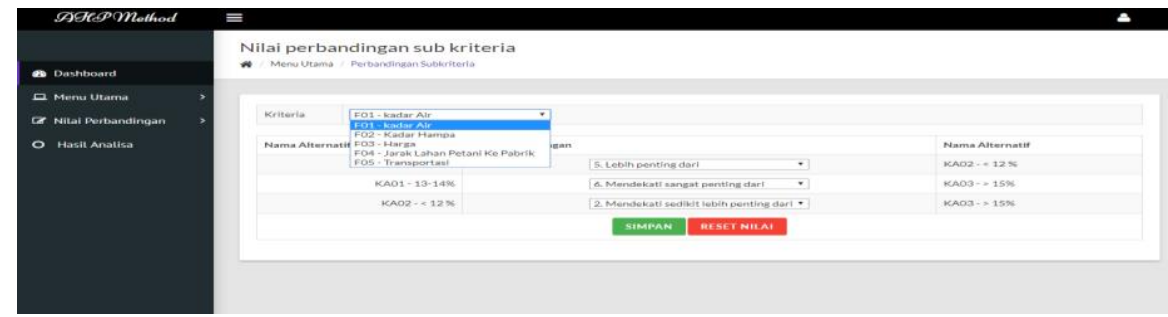

Gambar 6 Menu Perbandingan Subkriteria 


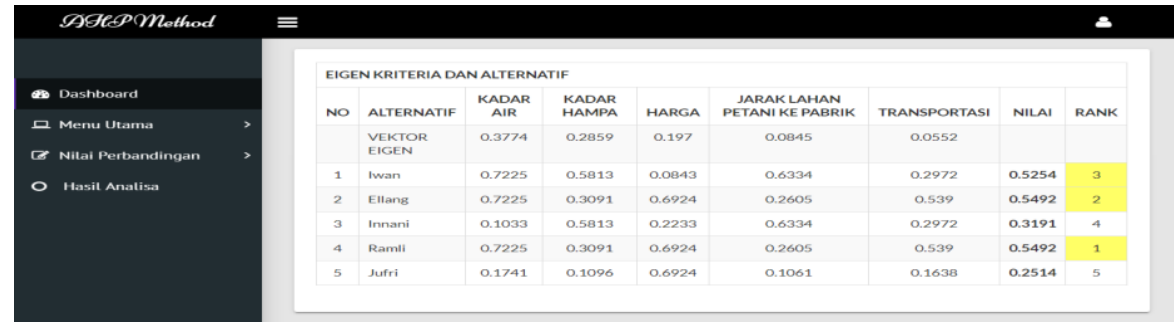

Gambar 7 Hasil Pemilihan Supplier

\subsection{Pengujian}

Penelitian ini menggunakan tiga cara pengujian sistem, cara pertama dengan pengujian fungsionalitas sistem menggunakan Black Box Testing dapat dilihat pada tabel 13

Tabel 13 Pengujian Fumgsinalitas

\begin{tabular}{|c|c|c|c|c|}
\hline No & $\begin{array}{l}\text { Komponen } \\
\text { Pengujian }\end{array}$ & Pengujian & Hasil yang diharapkan & $\begin{array}{c}\text { Hasil } \\
\text { Pengujian } \\
\end{array}$ \\
\hline \multirow[b]{2}{*}{1} & \multirow[b]{2}{*}{ Login User } & $\begin{array}{l}\text { Melakukan proses login sesuai } \\
\text { dengan akun user yang terdaftar }\end{array}$ & $\begin{array}{l}\text { Sistem dapat diakses apabila user } \\
\text { berhasil melakukan proses login }\end{array}$ & Diterima \\
\hline & & $\begin{array}{l}\text { Melakukan proses login dengan } \\
\text { memasukkan data user dan password } \\
\text { yang salah }\end{array}$ & $\begin{array}{l}\text { Sistem dapat menampilkan dialog } \\
\text { apabila user salah memasukkan user } \\
\text { dan password }\end{array}$ & Diterima \\
\hline 2 & Menu Kriteria & $\begin{array}{l}\text { Melakukan proses tambah, ubah, dan } \\
\text { hapus data kriteria }\end{array}$ & $\begin{array}{l}\text { Sistem dapat melakukan proses } \\
\text { tambah, ubah, dan hapus data kriteria }\end{array}$ & Diterima \\
\hline 3 & $\begin{array}{l}\text { Menu Alternatif } \\
\text { Supplier }\end{array}$ & $\begin{array}{l}\text { Melakukan proses tambah, ubah, dan } \\
\text { hapus data supplier }\end{array}$ & $\begin{array}{l}\text { Sistem dapat melakukan proses } \\
\text { tambah, ubah, dan hapus data supplier }\end{array}$ & Diterima \\
\hline \multirow{2}{*}{4} & \multirow{2}{*}{$\begin{array}{l}\text { Menu } \\
\text { Perbandingan } \\
\text { Kriteria }\end{array}$} & $\begin{array}{l}\text { Melakukan proses perbandingan, } \\
\text { simpan, cek konsistensi dan reset } \\
\text { nilai }\end{array}$ & $\begin{array}{l}\text { Sistem dapat melakukan proses } \\
\text { perbandingan, simpan, cek konsistensi } \\
\text { dan reset nilai }\end{array}$ & Diterima \\
\hline & & $\begin{array}{l}\text { Melakukan proses perbandingan } \\
\text { dengan memasukkan nilai yang tidak } \\
\text { konsisten }\end{array}$ & $\begin{array}{l}\text { Sistem dapat menampilkan dialog } \\
\text { apabila user salah dalam melakukan } \\
\text { perbandingan }\end{array}$ & Diterima \\
\hline 5 & $\begin{array}{l}\text { Menu } \\
\text { Perbandingan } \\
\text { SubKriteria } \\
\end{array}$ & $\begin{array}{l}\text { Melakukan proses perbandingan, } \\
\text { simpan, dan reset nilai }\end{array}$ & $\begin{array}{l}\text { Sistem dapat melakukan proses } \\
\text { perbandingan, simpan, dan reset nilai }\end{array}$ & Diterima \\
\hline 6 & $\begin{array}{l}\text { Menu Hasil } \\
\text { Analisa }\end{array}$ & $\begin{array}{l}\text { Menampilkan hasil perbandingan } \\
\text { Kriteria, Sub Kriteria dan } \\
\text { Perangkingan Supplier yang terpilih }\end{array}$ & $\begin{array}{l}\text { Sistem dapat menampilkan hasil } \\
\text { perbandingan Kriteria, Sub Kriteria dan } \\
\text { Perangkingan Supplier yang terpilih }\end{array}$ & Diterima \\
\hline
\end{tabular}

Berdasarkan pengujian fungsionalitas yang telah dilakukan semua komponen yang diujikan $100 \%$ berhasil dilakukan.

Pengujian kedua merupakan tahap uji akurasi dengan mencocokkan hasil keluaran pada sistem dengan data perankingan sebenarnya dari pihak PB Hikmat Tiga Berlian. Pengujian dilakukan sebanyak 5 kali dengan menginputkan nilai data nilai supplier yang berbeda pada masing-masing percobaan pada tabel 14 .

Tabel 14 Pengujian Tingkat Akurasi metode AHP

\begin{tabular}{cllll}
\hline Pengujian-Ke & \multicolumn{1}{c}{ Hasil Perangkingan Sistem } & Hasil Perankingan Manual & Hasil Uji (\%) \\
\hline Satu & Jufri - Innani - Ramli - Ellang - Iwan & Jufri - Innani - Ramli - Ellang - Iwan & $100 \%$ \\
\hline Dua & Ramli - Ellang - Innani - Iwan - Jufri & Ramli - Ellang - Innani - Iwan - Jufri & $100 \%$ \\
\hline Tiga & Ellang - Jufri - Iwan - Innani - Ramli & Ellang - Jufri - Iwan - Innani - Ramli & $100 \%$ \\
\hline Empat & Ramli - Ellang - Iwan - Innani - Jufri & Ramli - Ellang - Iwan - Innani - Jufri & $100 \%$ & $100 \%$ \\
\hline Lima & Innani - Jufri - Ramli - Ellang - Iwan & Innani - Jufri - Ramli - Ellang - Iwan & \\
\hline & Rata-Rata & & $\mathbf{1 0 0 \%}$ \\
\hline
\end{tabular}

Berdasarkan pengujian pada tabel 14 dengan acuan nilai $\lambda$ maks $=5,1140, C I=0,0285$ dan $C R$ $=0,0254$ tersebut tidak ditemukan perbedan hasil perangkingan sehingga didapatkan rata-rata tingkat akurasi untuk kedua metode ini adalah $100 \%$.

Pengujian ketiga menggunakan User Acceptance Test untuk mengetahui tingkat akurasi penerimaan prototype kepada user seperi pada tabel 15 
Tabel 15 Pengujian User Acceptance Test

\begin{tabular}{|c|c|c|c|c|c|c|}
\hline \multirow{2}{*}{ No } & \multirow{2}{*}{ Pertanyaan } & \multicolumn{5}{|c|}{ Persentase Responden (\%) } \\
\hline & & SS & $\mathbf{S}$ & $\mathbf{R}$ & KS & TS \\
\hline 1 & $\begin{array}{l}\text { Prototipe yang di iplementasikan dapat digunakan untuk menyeleksi } \\
\text { Supplier yang terpilih. }\end{array}$ & 70 & 20 & 10 & 0 & 0 \\
\hline 2 & $\begin{array}{l}\text { Prototipe memiliki kriteria penilaian yang sesuai dengan syarat yang } \\
\text { ditentukan pemilik untuk menghasilkan beras yang berkualitas. }\end{array}$ & 80 & 20 & 0 & 0 & 0 \\
\hline 3 & $\begin{array}{l}\text { Prototipe memberikan keleluasaan kepada pemilik untuk menambahkan } \\
\text { kriteria dan alternatif supplier. }\end{array}$ & 60 & 30 & 0 & 10 & 0 \\
\hline 4 & $\begin{array}{l}\text { Prototipe memberikan keleluasaan kepada anda untuk merubah nilai } \\
\text { perbandingan kriteria dan sub kriteria. }\end{array}$ & 50 & 40 & 10 & 0 & 0 \\
\hline 5 & $\begin{array}{l}\text { Peringkat yang dihasilkan oleh Sistem Pedukung Keputusan Pemilihan } \\
\text { Supplier Hasil Tani Gabah Menggunakan Metode AHP di PB. Hikmat } \\
\text { Tiga Berlian ini dapat digunakan untuk menyeleksi Supplier yang } \\
\text { memiliki hasil tani gabah yang berkualitas. }\end{array}$ & 80 & 20 & 0 & 0 & 0 \\
\hline & TOTAL & 68 & 26 & 4 & 2 & 0 \\
\hline
\end{tabular}

Berdasarkan hasil pengujian pada tabel 15 menghasilkan grafik pengujian User Acceptance Test seperti pada gambar 8. Grafik Hasil Uji User Acceptance

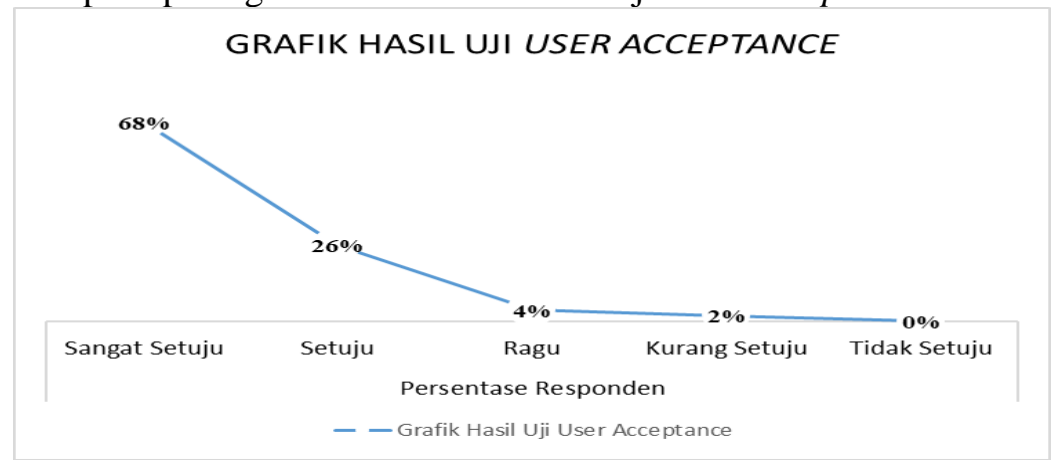

Gambar 8 Grafik Uji User Acceptance

Berdasarkan hasil pengujian User Acceptance Test dengan menggunakan 10 Respondent dan 5 pertanyaan bahwa sistem dengan menggunakan metode AHP Dalam pemilihan Supplier dapat diterapkan. Hal ini didasarkan pada nilai rata-rata hasil $68 \%$ responden menjawab Sangat Setuju dan $26 \%$ responden menjawab Setuju.

\section{KESIMPULAN}

Berdasarkan hasil dari tiga cara pengujian, yang pertama terhadap pengujian fungsionalitas yang telah dilakukan semua komponen yang diujikan $100 \%$ berhasil dilakukan. Dilanjutkan dengan tahap uji akurasi sebanyak 5 kali percobaan dengan nilai data supplier yang berbeda, menghasilkan tingkat akurasi sebesar $100 \%$. Berdasarkan 5 kali percobaan dengan nilai acuan $\lambda$ maks $=5,1140, C I=0,0285$ dan $C R=0,0254$ untuk dapat menjadi 3 peringkat teratas maka supplier perlu memiliki kualitas gabah dengan kadar air diantara 13\% - 14\%, kadar hampa diantara $1 \%$ - 3\%, patokan harga sekitar Rp4.600 - Rp5.000/Kg, jarak lahan petani ke pabrik sekitar $<5 \mathrm{Km}$ dan bebas memilih transportasi yang akan digunakan.

Pengujian User Acceptance Test dengan menggunakan 10 Respondent dan 5 pertanyaan bahwa sistem dengan menggunakan metode AHP Dalam pemilihan Supplier dapat diterapkan. Hasil pengujian User Acceptance Test diperoleh persentasi sebesar 68\% atas jawaban sangat setuju dan $26 \%$ responden menjawab kurang setuju.

\section{SARAN}

Dari hasil penelitian ini, maka untuk selanjutnya bisa melakukan pengembangan sistem dimana menggunakan kombinasi metode agar dapat membandingkan efektivitas dari metode AHP. Dapat juga dilakukan pengembangan sistem dengan menambahkan keterangan pada 
keputusan sistem alasan tidak terpilihnya supplier berdasarkan kriteria-kriteria yang tidak terpenuhi.

\section{DAFTAR PUSTAKA}

[1] Kusrini, 2008, Konsep dan Aplikasi Sistem Pendukung Keputusan , Andri Offset, Yogyakarta.

[2] Handayani, Rani Irma ,Darmianti, Y, 2017, Sistem Pendukung Keputusan Pemilihan Supplier Dengan Metode Analytical Hierarchy Process Pada PT . Cipta Nuansa Prima Tangerang. Jurnal Techno Nusa Mandiri, Vol 14, hal 103-110.

[3] Kosasi, S., \& Yuliani, I. D. A. E, 2014, Sistem Penunjang Keputusan Pemilihan Sales Promotion Girl, Jurnal Eksplora Informatika, Vol 4, hal 33-42.

[4] Sauter, Vicki L., 2011, Decision Support Systems for Business Intelligence, Second Edition, John Wiley \& Sons, Inc.

[5] Anu, J., Aby, K, A., Jacob, K, 2014, AHP Approach for Vendor Evaluation and Selection in a FMCG Company, International Journal of Emerging Technology and Advanced Engineering, Vol 4, hal 408-415.

[6] Hajar, Y. A. A, 2017, Using Analytical Hierarchy Process (AHP) to Build Suppliers' Selection Model. International Journal of Academic Research in Business and Social Sciences, 6(12), 772-787. https://doi.org/10.6007/ijarbss/v6-i12/2552.

[7] Xuan, T, N., Gu-Hong, L., Ngoc, B, T, N., 2016, Application of AHP Method in Analysing and Selecting the Right Supplier-Case of Instant Coffee Supplier for Hanoi Big C Supermarket, International Conference on Computational Intelligence and Applications, pp. 51-55.

[8] Rizka, H, Doddy, R, Syurfah, A. I, Rendra, I, 2017, Decision support systems: transportation mode selection for agricultural product distribution, Proceeding International Joint Conferenceon Science and Technology (IJCST), pp. 536-539..

[9] Amini, S., \& Asoodar, M. A., 2016, Selecting the most appropriate tractor using Analytic Hierarchy Process - An Iranian case study. Information Processing in Agriculture, 3(4), 223-234. https://doi.org/10.1016/j.inpa.2016.08.003.

[10] Sinaga, B., \& Zabua, H. M., 2014, Sistem Pendukung Keputusan Siswa Berprestasi Menggunakan Metode Analytic Hiearchy Process (AHP) Pada SMK Singosari Delitua. Jurnal Mantik Penusa, 16(2), 1-11. https://doi.org/10.1183/09031936.00190208

[11] Wahyu, S, P., Kusrini, Hanif, A. F., 2018, Sistem Pendukung Keputusan Pemilihan Produk Asuransi Studi Kasus : PT Commonwealth Life Pontianak, Jurnal Ilmiah SISFOTENIKA, Vol. 8, hal 105-116.

[12] Mulyono, S., 1996, Teori Pengambilan Keputusan, Lembaga Penerbit Fakultas Ekonomi Indonesia, Jakarta.

[13] Nur Heri Cahyana, 2010, "Teknik Permodelan Analitycal Hierarchy Proces (AHP) Sebagai Pendukung Keputusan”, Jurnal TELEMATIKA, ISSN : 1829-667X Vol. 6. 